Araştırma Makalesi

\title{
Ülke Kredi Notları ve Temel Makroekonomik Değişkenler Arasındaki İlişkinin Ekonometrik Analizi: Üst Orta Gelirli Ülkeler Üzerine Bir Uygulama ${ }^{1}$
}

\author{
Atakan DURMAZ \\ Samsun Üniversitesi, İ̈BF, Să̆lık Yönetimi Bölümü, \\ atakan.durmaz@samsun.edu.tr,ORCID:0000-0003-0374-9757 \\ Ümit YILDIZ \\ Sorumlu Yazar, Bayburt Üniversitesi, İ̈BF, İktisat Bölümü, \\ umityildiz@bayburt.edu.tr,ORCID:0000-0002-2677-2098
}

\begin{abstract}
$\ddot{O} \mathbf{z}$
Ülke kredi notları ile temel makroekonomik değişkenler arasındaki ilişkinin araştırıldığı çalıșmada, Standart and Poors (S\&P) tarafından derecelendirilen 32 ülkeye ait ülke kredi notları ve beş açılayıcı değişken 20082017 dönemi kapsamında panel sıralı probit modeliyle incelenmiştir. Elde edilen sonuçlara göre, kişi başına düşen gelir yükseldikçe kredi notlarının $\mathrm{BB}+$ ve altında yer alan düzeylerde olma ihtimali azalırken, yatırım yapılabilir seviye olan BBB- ve üzeri kredi notlarına sahip olma olasılığı artmaktadır. Üst orta gelir grubunda yer alan ülkelerde kişi başına düşen gelirde meydana gelen artış, en çok BB- notuna geçme ihtimalini azaltırken, yine en çok BBB düzeyine yükselme ihtimalini arttırmaktadır. Enflasyon ve faizde ise bu durumun tersi geçerlidir. Fiyatlar genel düzeyi ve faiz oranı yükseldikçe, üst orta gelir grubunda yer alan bir ülkenin yatırım yapılabilir seviyeye yükselme olasılığı azalmakta, spekülatif seviyede kalma olasılığı ise artmaktadır. Fiyatlar genel düzeyinde yaşanan artış çalışmaya konu olan ülkelerin kredi notunun BB- düzeyinde olma ihtimalini kuvvetli şekilde artırırken, BBB gibi yatırım yapılabilir bir düzeyde olma ihtimalini ise kuvvetli derecede azaltmaktadır. Öte yandan ilgili dönemde, üst orta gelir grubunda yer alan ülkeler için işsizlik oranı ve döviz kuru ile ülke kredi notları arasında sistematik bir ilişki görülmemiştir.
\end{abstract}

Anahtar Kelimeler: Makroekonomik Değişkenler, Ülke Kredi Notları, S\&P, Sıralı Probit Model JEL Sinıflandırması: E00, G24, C33

Econometric Analysis of the Relationship Between Sovereign Credit Ratings and Basic Macroeconomic Variables: An Application on the Upper Middle Income Countries ${ }^{2}$

\begin{abstract}
In the study beeing investigated therelationship between sovereign credit ratings and basic macroeconomic variables, sovereign credit ratings of 32 countries rated by Standard and Poors (S\&P) and five independent variables were examined within the 2008-2017 period by using panel ordered probit model. The results show that as per capita income rises, the likelihood of credit ratings at $\mathrm{BB}+$ and lower levels is reduced, increasing the likelihood of having an investment grade BBB- and credit ratings on it. The increase in the per capita income in the countries in the upper middle income group increases the likelihood of reaching the highest BBB level while decreasing the possibility of passing the BB-. The opposite is true for inflation and interest rates. As the general level of prices and the interest rate increase, the rate of increase of the investable level of an upper middle income group decreases and the rate of speculative level increases. While the increase in the general level of prices has strongly increased the likelihood that the countries subject to the study are at the BB- level of the credit rating, it is also strongly reducing the likelihood of being at an investable level such as $\mathrm{BBB}$. On the other hand, there is no systematic relationship between soverign creditratings and the unemployment rate and the exchange rate for the countries in the upper middle income group.
\end{abstract}

Keywords: Macroeconomic Variables, Sovereign Credit Ratings, S\&P, Ordered Probit Model JEL Classification: E00, G24, C33

\footnotetext{
${ }^{1}$ Bu çalışma Türkiye Ekonomi Kurumu, 6. Uluslararası Ekonomi Konferansı'nda tam metin bildiri olarak sunulmuştur.

${ }^{2}$ Extended abstract is presented at the end of the article.
}

Geliş Tarihi (Received): 15.11.2018 - Kabul Edilme Tarihi (Accepted): 18.12.2019

Atıfta bulunmak için/Cite this paper:

Durmaz A. ve Yıldız, Ü. (2019). Ülke kredi notları ve temel makroekonomik değişkenler arasındaki ilişkinin ekonometrik analizi: Üst orta gelirli ülkeler üzerine bir uygulama. Çankırı Karatekin Üniversitesi IİBF Dergisi, 9 (2), 365-380. 


\section{Giriş}

Sanayi devriminin yerini bilgi devrimine bıraktığı 21. yy’de, teknolojik ilerlemelerin etkisini hemen hemen her alanda görmek mümkündür. Yaşanan bu teknolojik gelişmelerle paralel şekilde gelişim gösteren ekonomik liberalizasyon ve küreselleşme süreçlerinin etkileri dünyanın bütün ekonomilerinde hissedilmiş ve pek çok ekonomik politikanın bu çerçevede şekillenmesine neden olmuştur. Ekonomik karar alma süreçleri üzerinde önemli değişikliklere neden olan bu gelişmelerin etkileri hem reel hem de finansal piyasalar üzerinde hissedilmiştir. $\mathrm{Bu}$ süreçte doğrudan yabancı sermaye yatırımlarının yanı sıra, küresel bir pazar haline gelen finansal piyasalardaki yatırımlarda da önemli gelişmeler yaşanmış ve bu durum yatırımcıların tüm pazarda esnek bir şekilde hareket etmelerine olanak sağlamıştır. Son dönemlerde yaşanan bu gelişmeler ise piyasa katılımcılarının diğer bir ifadeyle, fon arz edenler ve talep edenlerin finansal pozisyon alırken karşı karşıya kalacakları riskleri belirleyebilmeleri için gerekli bilgi donanımına sahip olmaları gerekliliğini ortaya çıkarmıştır.

$\mathrm{Bu}$ durum derecelendirme işlemine olan ihtiyacı ortaya çıkarmıştır. Bu doğrultuda kurulan kredi derecelendirme kuruluşları (CRA) farklı değişkenleri kullanarak devletlerin kredi verilebilirliğini ölçen bağımsız bir kredi notu hazırlamaktadır. Her bir bağımsız kredi notu, devletin kredi itibarını etkileyen farklı faktörleri değerlendiren bir derecelendirme komitesi tarafından belirlenir. Bu ülke notları bir ülkenin finansal gelişiminin önemli bir göstergesi haline gelmiştir. Nitekim çoğu yatırımcı tarafından bu notlar, bir ülkenin kredibilitesi ve hükümetinin borcunu tam ve zamanında yerine getirme konusundaki istek ve istekliliğinin bir göstergesi olarak değerlendirmektedir (Bissoondoyal-Bheenick, 2005).

Ülke notları, ülkelerin uluslararası finansal piyasalarda kredi alabilecekleri faiz oranlarını etkilemektedir. Bir ülkenin derecelendirme geçmişi, ülkelere kredi ve yardım sağlayan Dünya Bankası ve IMF gibi uluslararası kuruluşlar için yararlıdır. Uluslararası portföylere sahip yatırımcılar ve yönetilen fonlar, yatırım ve kredi kararları alırken devlet notlarını da izlemektedir. Dolayısıyla, ülke notları bir ülkenin küresel sermaye piyasalarına erişimini etkilemektedir. Ülke notları, genellikle, şirket ve diğer kurumlara verilen dereceler için bir tavan görevi de görür. Faiz oranı tespiti ayrıca faiz oranı paritesi üzerinden döviz kuru ile ilişkilendirilir. Döviz kurları, bir ülkenin uluslararası ticareti, yatırımları ve diğer sermaye akımları üzerinde doğrudan etkileri vardır.

Bu noktadan hareketle hazırlanan bu çalışmanın amacı; ülke kredi notları ile temel makroekonomik değişkenler arasındaki ilişkinin tespit edilmesidir. Bu doğrultuda, S\&P tarafından derecelendirilen 32 ülkeye ait ülke kredi notları ve beş açıklayıcı değişken 2008-2017 dönemi kapsamında incelenmiştir. Çalışma bu giriş kısmıyla birlikte literatür, veri seti ve yöntem, bulgular ile sonuç başlıkları olmak üzere beş kısımdan oluşmaktadır. 


\section{Literatür}

İlgili literatürde, Cantor ve Packer (1996) tarafından yapılan araştırma, ülke notu ve belirleyicileri alanındaki ön çalışmalardan biridir. Cantor ve Packer (1996) 49 ülke örneğini incelemiş ve Moody's ve S\&P tarafindan sağlanan derecelendirmenin belirleyicileri olarak sekiz ekonomik değişken kabul etmiştir. Kişi başına düşen gelir, gayri safi yurtiçi hasıla (GSYİH) büyümesi, enflasyon, dış borç, ekonomik gelişme düzeyi ve temerrüt geçmişi olmak üzere altı değişkenin ülke notlarını önemli ölçüde etkilediğini tespit etmişlerdir. Benzer şekilde, Afonso (2003), Moody's ve S\&P tarafindan 2001 y1lı için 81 ülkede kredi notu derecelerinin belirlenmesinde kullanılan faktörleri araştırmış ve aynı değişkenlerin derecelendirmeleri önemli ölçüde belirlediğini tespit etmiştir. Canuto, Dos Santos ve Porto (2012), 1998'den 2002'ye kadar olan panel verilerini kullanarak ülke notlarının belirleyicilerini araştırdıkları çalışmada ise, derecelendirme notlarının kişi başına GSYİH, enflasyon, ekonomik büyüme ve ticari açıklık gibi değişkenler tarafından belirlendiği sonucuna ulaşmışlardır.

Literatürdeki ilk çalışmalarda ülke kredi notlarının belirleyici olarak nicel makroekonomik değişkenler vurgulanırken, daha sonraki çalışmalarda niteliksel faktörlerin de bu notların belirlenmesinde önemli belirleyiciler olduğu belirtilmiştir. Bissoondoyal-Bheenick (2005), 95 ülkeye ait Aralık 1995-Aralık 1999 dönemini kapsayan veriler yardımıyla, ülke notlarının belirleyicilerini tespit etmeye çalıştığı çalışmada, ülke kredi notlarının belirlenme sürecinde kalitatif politik ve sosyal göstergelerin de kişi başına düşen gayri safi milli hasıla (GSMH) ve enflasyon gibi ekonomik değişkenlerle birlikte önemli olduğunu gözlemlemiştir. Butler ve Fauver (2006), bir ülkenin yasal ve siyasi kurumlarının, hukukun üstünlüğü, siyasi istikrar, yolsuzluk kontrolü, hükümetin etkinliği ve düzenleyici niteliği gibi etkenlerin, ülke derecelendirme sürecini önemli ölçüde etkilediğini tespit etmiştir. Mellios ve Paget-Blanc (2006) de çalışmalarında, FitchRatings, Moody's ve S\&P tarafindan belirlenen ülke kredi notlarının belirleyicilerini incelemiştir. Temel bileşen analizi yardımıyla 13 etken belirledikleri çalışma sonuçlarına göre, ülke notlarının çoğunlukla kişi başına düşen gelir, hükümet gelirleri, reel döviz kuru değişiklikleri, enflasyon oranı ve varsayılan tarihlerden etkilenmektedir. Çalışmada, Yolsuzluk Algı Endeksi (CPI) de ülke notlarını etkileyen önemli faktörlerden birisi olarak değerlendirilmektedir. Benzer şekilde, Afonso, Gomes ve Rother (2007) ülke notları belirlenirken kişi başına GSYİH, GSYİH büyümesi, devlet borçları, dış borçlar, dış rezervler ve varsayılan tarih gibi makroekonomik değişkenler ile birlikte hükümet etkinliği göstergelerinin de etkili olduğu sonucuna ulaşmıştır. Afonso, Gomes ve Rother (2011) tarafından yürütülen bir başka çalışma ise, ülke notlarının kısa vadede ve uzun vadede belirleyicileri arasında ayrım ortaya konulmaya çalışılmıştır. Elde edilen sonuçlara göre, kişi başına düşen GSYİH, GSYİH büyümesi, hükümet borçları ve devlet dengesindeki değişiklikler kısa vadede derecelendirmeler üzerinde etkili olduğu, hükümet etkililiği, dış borç, yabancı rezervler ve 
varsayılan tarihinin ise uzun vadede derecelendirmeler üzerinde önemli bir etkisi olduğu söylenebilmektedir. Şahinöz ve Gönenç (2011) çalışmasında, makroekonomik göstergelerden para politikası araçları ve kurumsal kalitenin ülke kredi notları üzerinde oldukça etkili olduğunu tespit etmişlerdir. Bu noktadan hareketle gelişmekte olan ülkelerin kredi notlarını yükseltmeleri için sürdürülebilir bir ekonomik büyüme ve borç yönetimi geliştirip, politik istikrarı sağlamaları gerektiğini tespit etmişlerdir. Gültekin-Karakaş, Hisarcıklılar ve Öztürk (2011) gelişmiş ve gelişmekte olan 106 ülkenin 1999-2010 dönemine ait verilerini kullanarak yaptıkları çalışmada, ülke kredi notlarını etkileyen faktörleri belirlemeye çalışmışlardır. Buna göre, gelişmekte olan ülkelerin kredi notlarını etkileyen faktörler arasında politik ve sosyal faktörler ön plana çıkarken, gelişmiş ülkelerde kredileri etkileyen en önemli faktör olarak makroekonomik etkenler gösterilmektedir. Pretorius ve Botha (2014) ise, dış denge, enflasyon, GSYİH büyüme ve yabancı rezervlere ek olarak, yolsuzluğun 27 Afrika ekonomisinin ülke notlarının önemli bir belirleyicisi olduğunu ortaya koymuştur. Arslan (2017) ise, kırılgan sekizlinin (Türkiye, Brezilya, Şili, Arjantin, Hindistan, Endonezya, Rusya ve G. Afrika) 2000-2015 yılları arasındaki verileri yardımıyla ülke kredi notları ile makroekonomik değişkenler arasındaki ilişkiyi incelemiştir. Elde edilen sonuçlara göre, işsizlik, toplam tasarruf, GSYİH, toplam rezervler, ihracat ve reel döviz kuru değişkenlerinin ülke kredi notları üzerinde etkisi söz konusu iken, işsizliğin bu ülkelerin kredi notları üzerinde bir etkisi söz konusu değildir. Çolak (2017) ise, Türkiye'nin 2005-2016 dönemine ait aylık veriler çerçevesinde ülke kredi notları ile makroekonomik değişkenler arasındaki nedenselliği araştırdığ 1 çalışmada, ülke kredi notları ile çalışmada kullanılan makroekonomik değişkenler arasında herhangi bir nedenselliğin bulunmadığı sonucuna ulaşılmıştır. Balıkçıoğlu ve Yılmaz (2019) çalışmada, 2000 sonrası dönemde karşılaştırmalı bir politika çerçevesinde maliye politikası ile ülke kredi notu arasındaki ilişki incelenmiştir. 12 gelişmiş ve gelişmekte olan ülkenin 2001-2016 dönemine ait verilerinin kullanıldığı çalışmada, kamu maliyesine ilişkin faktörlerin kredi notlarını farklılaştıran önemli etkenler olduğu sonucuna ulaşılmıştır.

Literatürde, farklı kurumların derecelendirme modellerini karşılaştırmak üzere yapılan çalışmalar da söz konusudur. Hill, Brooks ve Faff (2010) çalışmasında, kredi kalitesi değerlendirmesindeki değişimi S\&P, Moody's ve Fitch ile karşılaştırmaktadır. Elde edilen sonuçlara göre, derecelendirme kuruluşlarının değerlendirmelerinde genellikle bir veya iki çentik ile değiştiğini gözlemlemiş̧lerdir. Ayrıca, belirleyicilere ajanslar tarafından farklı önem verildiği ve derecelendirme kurumları arasında heterojenliğin var olduğu sonucuna ulaşılmıştır. Iyengar (2012) Moody's ve S\&P'nin derecelendirmelerini karşılaştırdığı çalışmasında, belirleyicilerin çoğunun derecelendirme kuruluşları arasında benzer olduğunu tespit etmiştir. Bununla birlikte, ajanslar tarafından verilen derecelendirmelerdeki ortalama farkın 2007'den 2010'a kadar zaman içerisinde arttığ1 görülmüştür. Zheng (2012), S\&P ve Dagong kredi derecelendirme kuruluşlarını karşılaştırdığı çalışmasında, her iki derecelendirme 
kuruluşunun ülke notlarını belirlemekte kullandığı birkaç ortak belirleyicinin olmasına karşın, derecelendirmeleri farklı öznel yargılar yoluyla yaptıklarını ortaya koymuştur.

Ayrıca literatürde, ülke notları ve belirleyicileri arasındaki ilişkiyi analiz etmek için alternatif metodolojik araçlar kullanan farklı araştırmacılar da söz konusudur. $\mathrm{Bu}$ kapsamda, ülke notu derecelendirmeleri üzerine yapılan Cantor ve Packer (1996); Afonso (2003); Alexe, Hammer, Kogan ve Lejeune (2003) gibi ilk çalışmalar doğrusal regresyon çerçevesinde hazırlanırken, Butler ve Fauver (2006) gibi çalışmalar ise, derecelendirme ölçeklerini doğrusal ve lojistik regresyonlara uygun olarak dönüştürmüştür. Elde edilen sonuçlara göre, lojistik dönüşümün daha iyi sonuçlar verdiği gözlemlenmiştir.

Bazı çalışmalar, ülke notu dereceleri ile belirleyicileri arasındaki ilişkiyi değerlendirmek için sıralı tercih modellerini kullanmıştır. Hu, Kiesel ve Perraudin (2002), derecelendirme geçiş matrislerini derecelendirmelere uyguladıkları çalışmada, aynı anda ülke dereceleri ve varsayılan deneyim için eşzamanlı olarak düzenlenmiş bir probit modelini tahmin etmişlerdir. Bissoondoyal-Bheenick (2005) ise çalışmasında düzenli bir yanıt modeli kullanmıştır. Mellios ve PagetBlanc (2006) hem doğrusal regresyon hem de siralı lojistik modelleri kullanmışlardır. Dahası, Afonso, Gomes ve Rother (2009), ülke borç notlarının belirleyicilerini, siralı logit, siralı probit ve rassal etkiler modelleri ile siralı probit kullanarak araştırmışlardır. Teker, Pala ve Kent (2013), faktör analizi kullanarak yeni bir derecelendirme metodolojisi geliştirmiş ve probit model teknikleri uygulamışlardır.

Literatür taraması, çeşitli araştırmacıların ülke kredi derecelerinin belirleyicileri olarak farklı bir değişken kümesi kullandığını göstermektedir. Spesifik değişkenleri seçmenin temeli veya mantığı açık değildir. Ayrıca, ülke notlarının belirleyicilerini incelemek için farklı metodolojiler uygulanmıştır.

\section{Veri Seti ve Yöntem}

Çalışmamızda, S\&P tarafindan belirlenen ülke kredi notları ile temel makroekonomik değişkenler arasındaki ilişkinin analizi yapılmaktadır. S\&P, her gelir gurubu için çok sayıda ülkeyi değerlendirmekte ve kredi notu belirlemektedir. Ancak, bu çalışmada Türkiye gibi üst orta gelir grubunda yer alan ülkeler analize dahil edilmiştir. Dünya Bankası sınıflandırmasına göre üst orta gelir grubunda 56 ülke yer almaktadır. Ancak söz konusu ülkelerin bir kısmı S\&P tarafından derecelendirilmemektedir. İlgili ülkelerin bir kısmının makroekonomik verilerine ise ulaşılamamaktadır. Bu nedenle üst orta gelir grubunda yer alan bazı ülkeler analize dahil edilmemiştir. Bu kapsamda Dünya Bankası tarafından üst 
orta gelir grubunda gösterilen $32^{3}$ ülkeye dair veriler panel veri ekonometrik teknikleri yardımıyla analiz edilmiştir.

Modele ait tanımlayıcı değişkenler temel makroekonomik değişkenlerden oluşmaktadır ve söz konusu değişkenler seçilirken literatür takip edilmiş ve S\&P derecelendirme kuruluşu tarafından incelenen değişkenler göz önüne alınmıştır. $\mathrm{Bu}$ anlamda Kişi Başına Düşen Gelir, Enflasyon, İşsizlik, Faiz ve Kur değişkenleri modellenmiştir.

Tablo 1: Modele Ait Açıklayıcı Değişkenler

\begin{tabular}{lll}
\hline \multicolumn{1}{c}{ Değişken } & \multicolumn{1}{c}{ Açıklaması } & Kaynak \\
\cline { 1 - 2 } KBGSYH & Sabit fiyatlarla KBGSYH (2010) & \\
\cline { 1 - 2 } Enflasyon & Tüketici Fiyatları Endeksi & \\
\hline İşsizlik & İşsizlik Oranı (ILO Modeli) & \\
\hline Faiz & Reel Faiz Oranı & \\
\cline { 1 - 2 } & Reel Efektif Döviz Kuru &
\end{tabular}

Çalışmada, 2008-2017 yılları için S\&P tarafından derecelendirilen 32 ülkeye ait ülke kredi notları ve 5 açıklayıcı değişkene ait panel veriler analiz edilmektedir. Söz konusu değişkenlere dair veriler Dünya Bankası veri tabanından elde edilmiştir. Verilerin analizinde Stata 12 ekonometri paket programından faydalanılmıştır.

$\mathrm{Bu}$ çalışmada ekonometrik model olarak Panel Sıralı probit modeli tercih edilmiştir. Burada sıralı bir modelin seçilmesinin nedeni modele ait bağımlı değişkenin kesikli bağımlı değişken adını verdiğimiz sıralı tam sayılardan oluşmasıdır. Kredi notlarının sıralı tam sayılara dönüştürülmesinde aşağıdaki doğrusal dönüşüm tablosundan faydalanılmıştır. Burada her bir yıla ait ülke kredi notu yılsonundaki kredi notunu (pozitif veya negatif görünüm hariç) temsil etmektedir.

Tablo 2: Doğrusal Dönüşüm Tablosu

\begin{tabular}{lllllllllll}
\hline \multicolumn{10}{c}{ Doğrusal Dönüșüm Tablosu } \\
\hline S\&P & AAA & AA+ & AA & AA- & A + & $\ldots \ldots$ & CCC & CCC - & CC & D \\
\hline & $\mathbf{2 1}$ & $\mathbf{2 0}$ & $\mathbf{1 9}$ & $\mathbf{1 8}$ & $\mathbf{1 7}$ & & $\mathbf{4}$ & $\mathbf{3}$ & $\mathbf{2}$ & $\mathbf{1}$
\end{tabular}

Kaynak: Afonso, Gomes ve Rother, 2007:34

\footnotetext{
${ }^{3}$ Arnavutluk, Azerbaycan, Belarus, Belize, Bosna-Hersek, Botsvana, Brezilya, Bulgaristan, Çin, Dominik Cumhuriyeti, Ekvator, Fiji, Güney Afrika, Jamaika, Karadağ, Kazakistan, Kolombiya, Kosta Rika, Lübnan, Makedonya, Malezya, Meksika, Paraguay, Peru, Romanya, Rusya, Surbistan, Surinam, Tayland, Türkiye, Ürdün, Venezüella.
} 


\subsection{Siral1 Tercih Modelleri}

Sıralı tercih modelleri (sıralı probit ve sıralı logit) bağımlı değişkenin sıralı tam sayılardan oluştuğu analizlerde başvurulan bir modeldir. Bu model, iki yönlü tercih modellerindeki gibi gözlenemeyen bir değişken varsayımı etrafında oluşturulur (Greene, 2003: 736). Aşağıdaki varsayım bağımlı değişken ' $y$ ' ile gözlenemeyen gizil değişken ' $y$ "' arasındaki ilişkiyi temsil etmektedir.

$$
y^{*}=x^{\prime} \beta+\varepsilon
$$

$$
\begin{gathered}
\mathrm{y}=0 ; \quad \mathrm{y}^{*} \leq 0 \text { ise } \\
=1 ; \quad 0<\mathrm{y}^{*} \leq \mu_{1} \text { ise } \\
=2 ; \quad \mu_{1}<\mathrm{y}^{*} \leq \mu_{2} \text { ise } \\
\quad \cdots{ }^{*} \quad \text { ise }
\end{gathered}
$$

$\mathrm{y}^{*}:$ gözlenemeyen gizil değişken

$\mathrm{x}$ : açıklayıcı değişkenler

$\varepsilon$ : hata terimi (standart dağılım)

$\mu$ : eşik değerleri (Cut points)

Modelde $\mathrm{y}^{*}$ gözlenemeyen gizil değişkeni, $\mathrm{x}$ açıklayıcı değişken vektörünü, $\varepsilon$ ise hata terimini temsil etmektedir. Siralı probit modelde hata teriminin normal dağıldığı varsayılır. Öte yandan $\mu$, y'nin alacağ 1 değerler için alt ve üst sınırları belirten eşik değerlerini göstermektedir. Eşik değerlerinin sayısı, bağımlı değişkenin alacağı değerlerin sayısına bağlıdır. Örneğin, 'y', 0,1 ve 2 değerlerini alıyorsa, modelde iki tane eşik değeri ( $\mu 1$ ve $\mu 2$ ) bulunmaktadır (Wooldridge, 2002: 505).

Normal dağılım varsayımı altında Sıralı Probit modeli için olasılıklar aşağıdaki şekilde formüle edilebilir (Greene, 2003: 737).

$$
\begin{aligned}
& \mathrm{P}(\mathrm{y}=0 \mid \mathrm{x})=\Phi\left(-\mathrm{x}^{\prime} \beta\right) \\
& \mathrm{P}(\mathrm{y}=1 \mid \mathrm{x})=\Phi\left(\mu_{1}-\mathrm{x}^{\prime} \beta\right)-\Phi\left(-\mathrm{x}^{\prime} \beta\right) \\
& \mathrm{P}(\mathrm{y}=2 \mid \mathrm{x})=\Phi\left(\mu_{2}-\mathrm{x}^{\prime} \beta\right)-\Phi\left(\mu_{1}-\mathrm{x}^{\prime} \beta\right) \\
& \mathrm{P}(\mathrm{y}=\mathrm{j} \mid \mathrm{x})=1-\Phi\left(\mu_{\mathrm{j}-1}-\mathrm{x}^{\prime} \beta\right)
\end{aligned}
$$

Sıralı probit modelinde tıpkı iki yönlü olasılık modellerinde olduğu gibi tahmin sonuçlarını temsil eden parametreler marjinal etkileri göstermez. Burada marjinal etkileri görebilmek için Sıralı Probit için tasarlanmış olasılık fonksiyonunun 
bağımsız değişkene göre türevi alınmaktadır. Örneğin 3 alternatifli $(0,1$ veya 2$)$ bir modelde tahmincilerin marjinal etkileri şu şekilde gösterilir (Greene, 2003: 738).

$$
\begin{aligned}
& \partial \operatorname{Prob}(\mathrm{y}=0 \mid \mathrm{x}) / \partial \mathrm{x}=-\Phi\left(\mathrm{x}^{\prime} \beta\right) \beta \\
& \partial \operatorname{Prob}(\mathrm{y}=1 \mid \mathrm{x}) / \partial \mathrm{x}=\left[\Phi\left(-\mathrm{x}^{\prime} \beta\right)-\Phi\left(\mu-\mathrm{x}^{\prime} \beta\right)\right] \beta \\
& \partial \operatorname{Prob}(\mathrm{y}=2 \mid \mathrm{x}) / \partial \mathrm{x}=\Phi\left(\mu-\mathrm{x}^{\prime} \beta\right) \beta
\end{aligned}
$$

Sıralı tercih modelleri panel veriler için de sıklıkla tercih edilmektedir. $\mathrm{Bu}$ çalışmada da panel sıralı tercih modellerinden olan rassal etkiler panel sıralı probit modelinden faydalanılmaktadır.

\subsubsection{Panel Siralı Probit Modeli}

Panel tercih modellerinin genel gösterimi şu şekildedir:

$$
\mathrm{y}_{\mathrm{it}}=\mathrm{x}_{\mathrm{it}}{ }^{\prime} \beta+\mathrm{u}_{\mathrm{i}}+\varepsilon_{\mathrm{it}}
$$

Burada $y_{i t}$ bağımlı değişkeni, $x_{i t}{ }^{\prime}$ bağımsız değişkenleri, $\varepsilon_{i t}$ rassal hata terimini ifade ederken, $u_{i}$ ise $i$ kadar birim için birim etkileri temsil etmektedir. Burada uygun modele karar verirken $\mathrm{u}_{\mathrm{i}}$ 'nin rassal olarak $\mathrm{m} 1$ yoksa sabit olarak $\mathrm{m} 1$ ele alınacağının belirlenmesi önemlidir. Ancak iki durum arasında tercih yapmak için kullanılacak uygun bir testin varlığı yaygın bir tartışma konusudur. Greene ve Hensher'e (2010) göre tercih modelleri için sabit etkiler tahmincisi uygun tahminci olsa dahi rassal parametre sorunundan dolayı elde edilen tahminciler tutarlı olmayacaktır. Bu çalışmada da $u_{i}$ 'nin nasıl ele alınacağına dair bir test yapılmamış, birim etkilerin rassal olduğu varsayımı altında rassal etkiler panel sıralı tercih modeli tercih edilmiştir.

Rassal etkiler panel sıralı tercih modellerinin genel yapısı şu şekildedir (Greene ve Hensher, 2010):

$$
\mathrm{y}_{\mathrm{it}}{ }^{*}=\beta^{\prime} \mathrm{x}_{\mathrm{it}}+\mathrm{u}_{\mathrm{i}}+\varepsilon_{\mathrm{it}}
$$

$$
\begin{aligned}
\mathrm{y}_{\mathrm{it}} & =1 ; \mathrm{y}_{\mathrm{it}}{ }^{*}<\mu_{1} \text { ise } \\
& =2 ; \quad \mu_{1} \leq \mathrm{y}_{\mathrm{it}}{ }^{*}<\mu_{2} \text { ise } \\
& =3 ; \quad \mu_{2} \leq \mathrm{y}_{\mathrm{it}}{ }^{*}<\mu_{3} \text { ise }
\end{aligned}
$$

Burada $y_{i t}{ }^{*}$ gözlenemeyen gizil değişkeni, $\beta$ ' bağımsız değişkenler vektörünü, $\alpha_{i}$ sabit etkileri, $\varepsilon_{i t}$ ise rassal hata terimini temsil etmektedir. $\mu$ ise bağımsız değişkenin alacağ j tane farklı alternatif için j-1 tane eşik değerini göstermektedir. 
Sıralı probit modellerde hata teriminin normal dağıldığı varsayılır. Normal dağılım varsayımıyla olabilirlik fonksiyonu Butler ve Moffitt yöntemiyle tahmin edilebilmektedir. Burada $v_{i}$ standartlaştırılmış değişken olarak uygun hale getirilerek $\left(u_{i}=\sigma v_{i}\right)$, her bir birim için ortak koşullu olasılık fonksiyonu şu şekilde ifade edilir (Greene ve Hensher, 2010):

$$
P\left(y_{i t}=j_{1}, y_{i t}=j_{2}, \ldots, y_{i t}=\mid X_{i}, v_{i}\right)
$$

\section{Bulgular}

$\mathrm{Bu}$ bölümde ülke kredi notları ile temel makroekonomik değişkenler arasındaki ilişkilerin belirlendiği tahmin sonuçlarına yer verilmektedir. Bu kapsamda panel sıralı probit tahmin sonuçlarını gösteren Tablo 3 ve her bir kredi notu için belirlenen marjinal etkilerin gösterildiği Tablo 4 hazırlanmıştır.

Tablo 3:Panel Sıralı Probit Tahmin Sonuçları

\begin{tabular}{lccc}
\hline & Katsayı & Standart Hata & Prob \\
\hline KBGSYH & 0.0002134 & 0.0000482 & 0.000 \\
\hline Enflasyon & -0.0213109 & 0.0042168 & 0.000 \\
\hline Faiz & -0.0229566 & 0.0106557 & 0.031 \\
\hline Kur & 0.0078080 & 0.0089646 & 0.384 \\
\hline İşsizlik & -0.0072687 & 0.0137235 & 0.596 \\
\cline { 1 - 1 } Prob> chi2 & & 0.0000 & \\
\cline { 1 - 1 } Pseudo R2 & & 0.00633 & \\
\cline { 1 - 1 } Loglikelihood & & -276.43979 & \\
\hline
\end{tabular}

Gelir, enflasyon ve faiz anlamlı değiş̧kenler. İkili tercih modellerinde olduğu gibi sıralı probit gibi çoklu tercih modellerinde de tahmin edilen katsayılar marjinal etkileri göstermemektedir. Burada katsayıların işareti yorumlanabilir. Buna göre kişi başına düşen gelirde meydana gelen artışlar kredi notunun yükselme olasılığını arttırırken, tüketici fiyatları endeksi ve faiz oranlarındaki artışlar kredi notlarının azalma ihtimalini arttırmaktadır. Bu sonuçlar 32 ülke ve analize konu olan tüm kredi notları için ortak sonuç olmakla birlikte, her bir kredi notunda olasılıkları ne düzeyde arttırdığı veya azalttığı hakkında tam bir fikir vermez. Bu nedenle istatistiksel olarak anlamlı olduğu tespit edilen gelir, enflasyon ve faiz değişkenlerinin her bir kredi notu için marjinal etkilerini incelemek sağlıklı olacaktır. Tablo 4'de söz konusu marjinal etkiler gösterilmektedir. Marjinal etkilerin tümü istatistiksel olarak anlamlıdır.

Çalışmada bağımlı değişkeni temsil eden kredi notları 21 farklı kredi notu içinden 13 farklı değer almaktadır. Diğer kredi notlarına dair frekanslar ise sifırdır. Çalışmada üst orta gelir grubuna dahil ülkelerle çalışıldığı için kredi notlarının genellikle spekülatif seviyeye yakın seyrettiği anlaşılmaktadır. Tablo incelendiğinde kişi başına düşen gelir yükseldikçe kredi notlarının spekülatif 
seviyeyi temsil eden $\mathrm{BB}+$ ve altında yer alan düzeylerde olma ihtimalini azaltırken, yatırım yapılabilir seviye olan BBB- ve üzeri kredi notlarına sahip olma olasılığını arttırmaktadır. Üst orta gelir grubunda yer alan ülkelerde kişi başına düşen gelirde meydana gelen artış, en çok BB- notuna geçme ihtimalini azaltırken, yine en çok BBB düzeyine yükselme ihtimalini arttırmaktadır.

Tablo 4.Marjinal Etkiler

\begin{tabular}{lccc}
\hline & KBGSYH & Enflasyon & Faiz \\
\hline CC & -0.00000137 & 0.00013730 & 0.00014790 \\
\hline B- & -0.00001480 & 0.00148130 & 0.00159570 \\
\hline B- & -0.00000932 & 0.00093110 & 0.00100300 \\
\hline B+ & -0.00001860 & 0.00185920 & 0.00200280 \\
\hline BB- & -0.00001970 & 0.00196960 & 0.00212170 \\
\hline BB & -0.00001850 & 0.00184600 & 0.00198850 \\
\hline BB+ & -0.00000276 & 0.00027520 & 0.00029650 \\
\hline BBB- & 0.00000774 & -0.00077300 & -0.00083270 \\
\hline BBB & 0.00002520 & -0.00251760 & -0.00271200 \\
\hline BBB+ & 0.00001630 & -0.00163280 & -0.00175890 \\
\hline A- & 0.00001740 & -0.00173800 & -0.00187220 \\
\hline A+ & 0.00000188 & -0.00018820 & -0.00020270 \\
\hline AA- & 0.00001650 & -0.00165010 & -0.00177760 \\
\hline & & &
\end{tabular}

Enflasyon ve faizde ise bu durumun tersi geçerlidir. Fiyatlar genel düzeyi ve faiz oranı yükseldikçe, üst orta gelir grubunda yer alan bir ülkenin yatırım yapılabilir seviyeye yükselme oranı azalmakta, spekülatif seviyede kalma oranı ise artmaktadır. Örneğin, fiyatlar genel düzeyinde yaşanan artış çalışmaya konu olan ülkelerin kredi notunun BB- düzeyinde olma ihtimalini kuvvetli şekilde artırırken, BBB gibi yatırım yapılabilir bir düzeyde olma ihtimalini kuvvetli derecede azaltmaktadir.

\section{Sonuç}

Özellikle son asırda mevcut ekonomik sistemde yaşanan dönüşümler dünyayı artık küresel bir pazar haline getirmiştir. $\mathrm{Bu}$ dönemde, küreselleşme ve liberalizasyon gibi olguların da etkisiyle ülkeler arasındaki sınırlar neredeyse tamamen kalkmıştır. Bu durum bireylerin, mal ve hizmetlerin küresel pazarda rahatça hareket edebilmesine olanak sağladığı gibi sermayenin ülkeler arasındaki transferinin önündeki engelleri de kaldırmıştır. Ancak sermayenin hangi ülkelere doğru hareket edeceği, sermaye sahipleri tarafından kolay verilebilecek bir karar değildir. Amacı kazanç elde etmek olan yatırımcının yatırım yapacağı ülkeye karar verirken ilgili ülkenin taşıdığı riskler hakkında bilgi sahibi olması gerekir. Ancak bu bilgiye sahip olmak her bir yatırımcı için açısından son derece güçtür. $\mathrm{Bu}$ da kredi derecelendirmesi adını verdiğimiz bir ihtiyacın doğmasına neden olmuştur. 
Kredi derecelendirmesi, kredi derecelendirme kuruluşları adını verdiğimiz bir takım bağımsız kuruluşlar tarafından yapılmaktadır. Kredi derecelendirmesi, bir finansal enstrüman, bir şirket veya bir kamu kurumu için yapılabileceği gibi bir ülke için de yapılabilir. Kredi derecelendirme kuruluşları çok sayıda iktisadi ve politik faktörü göz önünde bulundurarak her bir ülke için bir kredi notu belirler ve bu notlar tüm piyasa aktörleri tarafından kolayca anlaşılabilecek birtakım alfa nümerik semboller ile ilan edilir. Söz konusu semboller ülkelerin kredibilitesi hakkında yatırımcıya fikir verir ve yatırımcı karşılaşacağı riskler hakkında bilgi sahibi olur.

Kredi derecelendirme kuruluşları ülke kredi notlarını belirlerken çok sayıda iktisadi ve politik faktörü modellemektedirler. Ancak söz konusu politik faktörler son derece muğlak ve yoruma açık değişkenler olarak karşımıza çıkmaktadır. Kredi derecelendirme kuruluşları bu yönüyle, özellikle 2008 Krizi sonrasında eleştirilere maruz kalmış ve belirledikleri kredi notlarının gerçeği yansıtmadığı konusunda sıklıkla eleştirilmiştir. Kredi derecelendirme kuruluşları tarafından göz önünde bulundurulan söz konusu politik faktörlerin yeterince şeffaf ve net olmaması, bu çalışmanın sınırlarının oluşturulmasında da etkili olmuştur. $\mathrm{Bu}$ kapsamda çalışmada politik faktörler göz ardı edilerek ülke kredi notları ile temel makroekonomik değişkenler arasındaki ilişki incelenmiştir.

Kredi derecelendirme kuruluşları tarafından ilan edilen ülke kredi notları çok sayıda çalışmaya konu olmaktadır. $\mathrm{Bu}$ çalışmada da, üç büyük kredi derecelendirme kuruluşundan biri olan S\&P'nin 32 üst orta gelirli ülke için belirlediği ülke kredi notları incelenmiş ve kredi notlarıyla temel makroekonomik değişkenler arasındaki ilişkiler araştırılmıştır. Çalışmanın bulgularında, kişi başına düşen gelir düzeyi, enflasyon oranı ve faiz oranı değişkenlerinin istatistiksel olarak anlamlı olduğu sonucuna varılmış ancak döviz kuru ve işsizlik oranı ile ülke kredi notları arasında sistematik bir ilişkiye rastlanılmamıştır.

Tahmin sonuçlarına göre çalışmaya konu olan 32 ülke için ilgili dönemde kişi başına düşen gelir düzeyindeki artışlar, ülke kredi notlarının daha üst bir seviyede gerçekleşme ihtimalini artırırken, enflasyon ve faiz oranındaki artışlar kredi notlarının daha düşük bir seviyeye gerileme riskini arttırmaktadır. İstatistiksel olarak anlamlı olduğu anlaşılan kişi başına düşen gelir, enflasyon oranı ve faiz oranı değişkenlerine ait marjinal etkiler incelendiğinde ise söz konusu değişkenlerin ülke kredi notları üzerindeki etkilerinin yatırım yapılabilir seviyede ve spekülatif seviyede farklılıklar gösterdiği anlaşılmaktadır. Ancak tahminlerin ortak sonucu olarak kişi başına düşen gelirdeki artışların ve enflasyon ve faiz oranında meydana gelen azalmaların ülkelerin yatırım yapılabilir seviyede kalma ihtimallerini arttırdığı görülmüştür. Tersi senaryoda ise ülkelerin spekülatif seviyede bir kredi notuna gerileme ihtimallerinin arttı̆̆ını söyleyebiliriz.

Sonuç olarak bu çalışmada, Türkiye gibi üst orta gelir grubunda yer alan ülkeler için gelir düzeyi ile enflasyon ve faiz oranlarının ülke kredi notunu belirleyen 
temel makroekonomik değişkenler olduğu sonucuna varılmış, döviz kuru ve işsizlik oranı ile ülke kredi notları arasındaki ilişki ise kanıtlanamamıştır. $\mathrm{Bu}$ durumda yatırım yapılabilir seviyede kredi notuna sahip olmak isteyen üst orta gelirli ülkelerin, gelir, enflasyon ve faiz değişkenlerindeki iyileştirmeleri amaçlayan politikalara odaklanmaları doğru olacaktır. Çalışmaya konu olan ülkeler genellikle gelişmekte olan ve yapısal dönüşümlerini henüz tam anlamıyla gerçekleştirememiş ülkelerden oluşmaktadır. $\mathrm{Bu}$ nedenle makroekonomik faktörlerdeki iyileştirmelerin yanı sıra makroekonomik istikrar da bu konuda son derece önem arz etmektedir. Öte yandan daha önce de bahsedildiği gibi çalışmada politik faktörlere yer verilmemiştir. Özellikle Türkiye gibi gelişmekte olan ülkelerde politik faktörler de en az iktisadi faktörler kadar yatırımcı kararlarını etkiler niteliktedir. Bu nedenle sonuç olarak şunu söyleyebiliriz ki; çalışmaya konu olan ülkelerin yatırım yapılabilir seviyede kredi notuna sahip olmalarının yolu makroekonomik göstergelerdeki iyileştirmelerin yanı sıra ülkelerin yapısı gereği hem iktisadi hem de politik istikrara sahip olmalarından geçmektedir. 


\section{Kaynakça}

Afonso, A. (2003). Understanding the determinants of sovereign debt ratings: evidence for the two leading agencies. Journal of Economics and Finance, 27(1), 56-74.

Afonso, A., Gomes, P. ve Rother, P. (2007). What hides behind sovereign debt ratings?, European Central Bank Working Paper Series, No:711

Afonso, A., Gomes, P. ve Rother, P. (2009). Ordered response models for sovereign debt ratings. Applied Economics Letters, 16(8), 769-773.

Afonso, A., Gomes, P. ve Rother, P. (2011). Short and long-run determinants of sovereign debt credit ratings. International Journal of Finance \& Economics, 16(1), 1-15.

Alexe, S., Hammer, P. L., Kogan, A.ve Lejeune, M. A. (2003). A nonrecursive regression model for country risk rating. RUTCOR Rutgers University Research Report RRR, 9, 1-40.

Arslan, S. (2017). Macroeconomic factors affecting the country credit 1nvestigations: an application on fragile eight. Press Academia Procedia (PAP), V.3, 197-205.

Balıkçıŏlu, B. ve Yılmaz, H. H. (2019). How fiscal policies affect credit rates: probit analysis of three main credit rating agencies' sovereign credit notes. Transylvanian Review of Administrative Sciences,56 E/February, 5-22.

Bissoondoyal-Bheenick, E. (2005). An analysis of the determinants of sovereign ratings. Global Finance Journal, 15(3), 251-280.

Butler, A.W. ve Fauver, L. (2006). Institutional environment and sovereign credi ratings. Financial Management, 35(3), 53-79.

Cantor, R. ve Packer, F. (1996). Determinants and impact of sovereign credit ratings. Economic Policy Review, 2(2), 37-54.

Canuto, O., Dos Santos, P. F. P. ve Porto, P. C. D. S. (2012). Macroeconomics and sovereign risk ratings. Journal of International Commerce, Economics and Policy, 3(2), 1250011-1250025.

Çolak, Y. (2017). Türkiye'nin makroekonomik değişkenleri ile kredinotları arasındaki nedensellik ilişkisi: Moody's örneği. Uluslararası Ekonomi, İsletme ve Politika Dergisi, 1(1), 61-74.

Greene, W.H. (2003). Econometric Analysis. New Jersey: Pearson Education

Greene, W.H. ve Hensher, D.A.(2010). Modelling ordered choices: a primer New York: Cambridge University Press

Gültekin Karakaş, D., Hisarcıklılar, M. ve Öztürk, H. (2011). Sovereign risk ratings: biased toward developed countries. EmergingMarkets Finance and Trade, 47(2), 69-87. 
Hill, P., Brooks, R.ve Faff, R. (2010). Variations in sovereign credit quality assessments across rating agencies. Journal of Banking \& Finance, 34, 1327-1343.

Hu, Y. T., Kiesel, R. ve Perraudin, W. (2002). Thes timation of transition matrices for sovereign credit ratings. Journal of Banking \& Finance, 26(7), 13831406.

Iyengar, S. (2012). The credit rating agencies - are they reliable? A study of sovereign ratings. Vikalpa, 37(1), 69-82.

Mellios, C. ve Paget-Blanc, E. (2006). Which factors determine sovereign credit ratings? The European Journal of Finance, 12, 361- 377.

Pretorius, M. ve Botha, I. (2014). A panel ordered response model for sovereign credit ratings in Africa, ERSA working paper 464. Retrieved from http://www.econrsa.org/system/files/publications/working_papers/working _paper_464.pdf. (Accessed: 22 March 2015).

Şahinöz, S. ve Gönenç, R. (2011), Determinants of credit ratings, sovereign bond spreads and real interest rates in emerging markets, Iktisat Işletme ve Finans, 26(305), 9-35.

Teker, D., Pala, A. ve Kent, O. (2013). Determination of sovereign rating: Factor based ordered probit models for panel data analysis modelling framework. International Journal of Economic and Financial Issues, 3(1), 122-132.

Wooldridge, J.M. (2002). Econometric analysis of crosssection and panel data. London: MIT Press.

Zheng, L. (2012). Are sovereign credit ratings objective? A tale of two agencies. Journal of Applied Finance \& Banking, 2(5), 43-61.

http://countryeconomy.com/ratings

http://databank.worldbank.org/ 


\section{Econometric Analysis of the Relationship Between Sovereign Credit Ratings and Basic Macroeconomic Variables: An Application on the Upper Middle Income Countries}

\section{Extended Abstract}

\section{Introduction}

In the 21 st century, when the industrial revolution was replaced by the information revolution, it is possible to see the impact of technological advances in almost every field. The effects of the processes of economic liberalization and globalization, which developed in parallel with these technological developments, have been felt in all economies of the world and caused many economic policies to be shaped within this framework. The effects of these developments, which caused significant changes in economic decision-making processes, were felt on both real and financial markets.

These recent developments have led to the necessity of the market participants to have the necessary information equipment in order to determine the risks that the fund supplyers and demanders will face when taking financial positions. This situation revealed the need for grading. As a matter of fact, many investors consider the ratings of these rating institutions as an indicator of the credibility of a country and the willingness and willingness of its government to fulfill its debt in full and on time. The aim of this study is; The determination of the relationship between the country's credit ratings and the main macroeconomic variables. Accordingly, the sovereign credit ratings of 32 countries rated by Standard and Poors and 5 explanatory variables were examined within the period of 2008-2017.

\section{Method}

In this study, the relationship between the national macroeconomic variables and the sovereign credit ratings determined by Standard and Poor's is analyzed. S\&P evaluates a large number of countries and sets a credit rating for each income group. However, countries such as Turkey, located in the upper-middle income groups in the study were included in the analysis. According to the World Bank classification, there are 56 countries in the upper middle income group. However, some of these countries are not rated by S\&P. Macroeconomic data of some countries are not available.

Therefore, some countries in the upper middle income group are not included in the analysis. In this context, the data of 32 countries which were shown by the World Bank in the upper middle income group were analyzed with the help of panel data econometric techniques. The descriptive variables of the model constitute the main macroeconomic variables and the literature was followed when selecting these variables and the variables examined by the S\&P rating agency were considered. In this sense, per capita income, inflation, unemployment, interest and exchange rate variables are modeled. In this study, the sovereign credit ratings of 32 countries and panel data of 5 explanatory variables are analyzed for the years 2008-2017. Data on these variables were obtained from the World Bank database. Stata 12 econometrics package program was used for data analysis.

In this study, Panel Ordered Probit Model was preferred as econometric model. The reason why a ordered choice model is selected here is that the dependent variable of the model consists of sequential integers which we call discrete dependent variable. 


\section{Results and Discussion}

According to the results, the increase in per capita income increases the likelihood of increasing the credit rating, while the increase in consumer price index and interest rates increases the likelihood of decreasing credit ratings. While these results are common to 32 countries and all credit ratings subject to analysis, they do not give a complete idea of the extent to which they increase or decrease the likelihood of each credit rating. Therefore, it will be healthy to examine the marginal effects of income, inflation and interest variables that are found to be statistically significant for each credit grade.

In the study, the credit grades representing the dependent variable take 13 different values. Since the study was conducted with countries included in the upper middle income group, it is understood that credit ratings are generally close to the speculative level. In this study, while the per capita income increases, it decreases the likelihood that the credit ratings will be at $\mathrm{BB}+$ and below levels, while increasing the probability of having BBB- and above investment grade. While the increase in per capita income in the upper middle income countries decreases the likelihood of passing to BB- grade, it increases the likelihood of increasing to BBB level.

The opposite applies to inflation and interest rates. The higher the general level and the interest rate, the lower the rate of rise in a country in the upper middle income group and the speculative level of increase. For example, the increase in prices at the general level strongly increases the likelihood of the credit rating of the countries subject to study at BB- level, while strongly decreasing the likelihood of being at an investable level like BBB.

\section{Conclusion}

According to the estimation results, the increase in the per capita income level for the 32 countries subject to the study increases the likelihood that the sovereign credit ratings will be realized at a higher level, while the increases in inflation and interest rates increase the risk of decreasing the credit ratings to a lower level. When the marginal effects of per capita income, inflation rate and interest rate variables, which are found to be statistically significant, are analyzed, it is understood that the effects of these variables on sovereign credit ratings vary at investment grade and speculative level. However, the increase in per capita income and the decrease in inflation and interest rates as a result of the estimations increased the likelihood of countries to remain at an investment level. In the opposite scenario, we can say that countries are more likely to decline to a speculative credit rating.

As a result, in this study, it is concluded that interest rates, income level and inflation are the main macroeconomic variables determining the upper middle-income sovereign credit rating. The relationship between exchange rate, unemployment rate and sovereign credit ratings has not been proved. In this case, upper middle-income countries wishing to obtain an investment grade credit rating should focus on policies aimed at improvements in income, inflation and interest variables. The countries that are the subject of the study are generally developing countries which have not yet fully realized their structural transformation. Therefore, in addition to improvements in macroeconomic factors, macroeconomic stability is extremely important. Especially in developing countries such as Turkey, political factors also affect the investment decisions at least until economic factors. Therefore, we can conclude that; In addition to the improvements in macroeconomic indicators, the economic and political stability of the countries as a result of the structure of the countries subject to the study is based on the investment grade. 